\title{
FALASIFA
}

Jurnal Studi Keislaman

\section{PERAN PENDIDIKAN AGAMA ISLAM DALAM PEMBENTUKAN KARAKTER SOSIAL DALAM BERMASYARAKAT}

\author{
Khurin'In Ratnasari \\ Yovita Dyah Permatasari \\ Mar'atus Sholihah \\ IAI Al-Falah As-sunniyyah Kencong \\ khurininatnasari@gmail.com
}

\begin{abstract}
Islamic religious education is very important for shaping character, especially in social society. In today's era, students tend not to care about society, therefore forming a good character is very important, especially in the social community in Islamic religious education itself, it teaches us that we are required to have good character as taught by the Prophet Muhammad; Allah SWT said, which means "and indeed you (Muhammad) have a noble character". Because of this, it can be concluded that the Prophet Muhammad, was sent to earth to improve the character of all human beings. Thus, the character of education from an Islamic point of view is needed, especially in Islamic educational institutions. So, from various problems related to morals which are ideally able to realize character education, especially in social society in an Islamic perspective in the form of mutual care. courtesy to parents. sense of responsibility and care for fellow human beings.
\end{abstract}

Keywords: Character Building of Islamic Religious Education Social Character

\begin{abstract}
Abstrak
Pendidikan Agama Islam sangat penting untuk pembentuk karakter khusunya dalam bersosial masyarakat. Di dalam era jaman sekarang anak didik cenderung tidak peduli dalam masyarakat oleh karena itu membentuk karakter yang baik sangatlah penting khusunya dalam sosial masyarakat dalam pendidikan agama islam sendiri mengajarkan bahwanya kita diwajibkan memiliki karakter yang baik sesuai yang diajarakan oleh Nabi Muhammad SAW; Allah SW'T berfirman, yang berarti "dan sesungguhnya engkau (Muhammad) memiliki karakter yang mulia“. Karena hal itu, dapat disimpulkan bahwa Nabi Muhammad, dikirim ke bumi tidak lain untuk memperbaiki karakter semua manusia. Dengan demikian, karakter pendidikan menurut sudut pandang islam diperlukan, terutama di lembaga pendidikan islam. Maka, dari berbagai masalah-masalah yang berkaitan dengan akhlak yang idealnya mampu mewujudkan pendidikan karakter khusunya di sosial masyarakat dalam perspektif islam dalam bentuk kepedulian sesama. kesopanan terhadap orangtua. rasa tanggung jawab dan rasa peduli kepada sesama manusia.

Kata Kunci : Pembentukan Karakter Pendidikan Agama Islam Karakter Sosial
\end{abstract}




\section{PENDAHULAN}

Pendidikan merupakan faktor utama dalam pembentukan karakter baik dan buruknya di dalam kehidupan sehari- hari. pendidikan anak tidak hanya di dapat dari sekolah melainkan dari lingkungan keluarga dan lingkungan masyarakat. Peran sekolah sangat penting dalam usaha pembentukan karakter. Dalam konteks tersebut, pendidikan karakter adalah usaha sekolah yang dilakukan secara bersama oleh guru, pimpinan sekolah ( dan warga sekolah) melalui kegiatan sekolah untuk membentuk akhlak, watak atau kepribadian peserta didik melalui berbagai kebaikan yang terdapat dalam ajaran agama. Bagi yang beragama Islam, mereka senantiasa menjadikan Al Qur'an sebagai landasan untuk cara pandang, berfikir, bersikap dan bertindak.

Peran sekolah sangat penting dalam usaha pembentukan karakter. Dalam konteks tersebut, pendidikan karakter adalah usaha sekolah yang dilakukan secara bersama oleh guru, pimpinan sekolah ( dan warga sekolah) melalui kegiatan sekolah untuk membentuk akhlak, watak atau kepribadian peserta didik melalui berbagai kebaikan (Virtues) yang terdapat dalam ajaran agama. Bagi yang beragama Islam, mereka senantiasa menjadikan Al Qur'an sebagai landasan untuk cara pandang, berfikir, bersikap dan bertindak. Fungsi utama sekolah adalah sebagai media untuk merealisasikan pendidikan berdasarkan tujuan pemikiran, akidah, syari'at demi terwujudnya penghambaan diri kepada Allah serta sikap mengesakan Allah dan mengembangkan segala bakat ayau potensi manusia sesuai dengan fitrahnya sehingga manusia terhindar dari berbagai penyimpangan. Fungsi tersebut jika dijabarkan antara lain, sekolah berfungsi sebagai tempat untuk memperluas wawasan dan pengalaman anak didik melalui transfer nilai dan ilmu, sebagai tempat untuk mewujudkan keterikatan, integrasi, homogenitas, dan keharmonisan antar siswa sebagai penyempurna tugas keluarga dalam pendidikan.

Pendidikan Agama Islam merupakan pondasi bagi kehidupan umat beragama islam. Dengan adanya pendiidkan agama sebagai wahana pembentukan karakter manusia yang bermoral tinggi. Dalam pendidikan islam tidak lepas dengan moral dan akhlak. Akhlak yang baik akan terbentuk karakter yang baik khususnya dalam lingkungan masyarakat dan pendidikan Agama Islam sudah diajarkan oleh Rosul kepada Umatnya bahwasanya agama islam mengacu kepada mengenal Allah berperilaku baik dan bahkan dalam pembentukan karakter yang baik sesuai yang diajakan oleh Nabi Muhammad SAW. Dijaman sekarang anak didik sudah mulai melupakan akhlak yang baik sepertihalnya dalam sosial masyarakat. Anak didik sekarang cenderung bersifat tidak peduli dalam lingkungannya dan 
jiwa sosial semakin kurang serta acuh tak acuh dan tidak bisa untuk diberitahu orang tua. Dengan adanya problematika tentang pendidikan karakter anak peneliti tertarik untuk meneliti pentingnya pendidikan agama islam dalam pembentukan karakter sosial masyarakat pada anak.

\section{PEMBAHASAN}

a. Pendidikan Agama Islam

Pendidikan Agama Islam merupakan salah satu dari tiga subyek pelajaran yang harus dimasukkan dalam kurikulum setiap lembaga pendidikan formal di Indonesia. Hal ini karena kehidupan beragama merupkan salah satu dimensi kehidupan yang diharapkan dapat terwujud secara terpadu. ${ }^{1}$

Dalam bahasa Indonesia, istilah pendidikan berasal dari kata "didik" dengan memberinya awalan "pe" dan akhiran "an", mengandung arti "perbuatan" (hal, cara atau sebagainya). Istilah pendidikan ini semula berasal dari bahasa Yunani "paedagogie", yang berarti bimbingan yang diberikan kepada anak. Istilah ini kemudian ditejemahkan dalam bahasa Inggris "education" yang berarti pengembangan atau bimbingan. Dalam bahasa Arab pengertian pendidikan, sering digunakan beberapa istilah antara lain, al-ta'lim, altarbiyah, dan al-ta'dib, al-ta'lim berarti pengajaran yang bersifat pemberian atau penyampaian pengetahuan dan ketrampilan. Al-tarbiyah berarti mengasuh mendidik dan alta'dib lebih condong pada proses mendidik yang bermuara pada penyempurnaan akhlak/moral peserta didik. ${ }^{2}$ Namun, kata pendidikan ini lebih sering diterjemahkan dengan “tarbiyah” yang berarti pendidikan. ${ }^{3}$ Dari segi terminologis, Samsul Nizar menyimpulkan dari beberapa pemikiran ilmuwan bahwa pendidikan merupakan usaha sadar yang dilakukan secara bertahap dan simultan (proses), terencana yang dilakukan oleh orang yang memiliki persayaratan tertentu sebagai pendidik. ${ }^{4}$ Selanjutnya kata pendidikan ini dihubungkan dengan Agama Islam, dan menjadi satu kesatuan yang tidak dapat diartikan secara terpisah. Pendidikan agama Islam (PAI) merupakan bagian dari pendidikan Islam dan pendidikan Nasional, yang menjadi mata pelajaran wajib di setiap lembaga pendidikan Islam. Pendidikan agama Islam sebagaimana yang tertuang dalam GBPP PAI di sekolah umum,

\footnotetext{
${ }^{1}$ Chabib Thoha, dkk, Metodologi Pengajaran Agama, (Yogyakarta : Pustaka Pelajar, 1999)

2 Samsul Nizar, Pengantar Dasar-dasar Pemikiran Pendidikan Islam Jakarta : Gaya Media Pratama, 2001) 86-88

${ }^{3}$ Ramayulis, Op. Cit. 13

${ }^{4}$ Samsul Nizar, Op. Cit. 92
} 
dijelaskan bahwa pendidikan agama Islam adalah upaya sadar dan terencana dalam menyiapkan peserta didik untuk mengenal, memahami, menghayati, hingga mengimani ajaran agama Islam, dibarengi dengan tuntutan untuk menghormati penganut agama lain dalam hubungannya dengan kerukunan antar umat beragama hingga terwujud kesatuan dan persatuan bangsa. ${ }^{5}$ Menurut Zakiyah Darajat (1987:87) pendidikan agama Islam adalah suatu usaha untuk membina dan mengasuh peserta didik agar senantiasa dapat memahami ajaran Islam secara menyeluruh. Lalu menghayati tujuan, yang pada akhirnya dapat mengamalkan serta menjadikan Islam sebagai pandangan hidup. Mata pelajaran pendidikan agama Islam secara keseluruhannya dalam lingkup Al-Qur'an dan Al-hadits, keimanan, akhlak, fiqh/ibadah, dan sejarah, sekaligus menggambarkan bahwa ruang lingkup pendidikan agama Islam mencakup perwujudan keserasian, keselarasan dan keseimbangan hubungan manusia dengan Allah SWT, diri sendiri, sesama manusia, makhluk lainnya maupun lingkungannya (hablun minallah wa hablun minannas).

b. Tujuan Pendidikan Agama Islam

Tujuan artinya sesuatu yang dituju, yaitu yang akan dicapai dengan suatu usaha atau kegiatan. Dalam bahasa arab dinyatakan dengan ghayat atau maqasid. Sedang dalam bahasa Inggris, istilah tujuan dinyatakan dengan "goal atau purpose atau objective" Suatu kegiatan akan berakhir, bila tujuannya sudah tercapai. Kalau tujuan tersebut bukan tujuan akhir, kegiatan selanjutnya akan segera dimulai untuk mencapai tujuan selanjutnya dan terus begitu sampai kepada tujuan akhir. ${ }^{7}$

Pendidikan agama Islam di sekolah / madrasah bertujuan untuk menumbuhkan dan meningkatkan keimanan melalui pemberian dan pemupukan pengetahuan, penghayatan, pengamalan, serta pengalaman peserta didik tentang agama Islam sehingga menjadi manusia muslim yang terus berkembangdalam hal keimanan, ketakwaannya, berbangsa dan bernegara, serta untuk dapat melanjutkan pada jenjang yang lebih tinggi. ${ }^{8}$ Penekanan terpenting dari ajaran agama Islam pada dasarnya adalah hubungan antar sesama manusia yang sarat dengan nilai-nilai yang berkaitan dengan moralitas sosial itu. Sejalan dengan hal ini, arah pelajaran etika di dalam al Qur'an dan secara tegas di dalam hadis Nabi mengenai diutusnya

\footnotetext{
${ }^{5}$ Muhaimin, Wacana.... Op. Cit 76

${ }^{6}$ M. Arifin, Ilmu Pendidikan Islam, (Jakarta : Bumi Aksara, 1991) 222

7 Zakiyah Daradjat, Metodologi ...Op. Cit. 72

8 Abdul Majid dan Dian Andayani, Op. Cit. 135
} 
Nabi adalah untuk memperbaiki moralitas bangsa Arab waktu itu. Oleh karena itu, berbicara pendidikan agama islam, baik makna maupun tujuannya haruslah mengacu pada penanaman nilai-nilai Islam dan tidak dibenarkan melupakan etika sosial atau moralitas sosial. Penanaman nilai-nilai ini juga dalam rangka menuai keberhasilan hidup (hasanah) di dunia bagi anak didik yang kemudian akan mempu membuahkan kebaikan (hasanah) di akhirat kelak.

c. Fungsi Pendidikan Agama Islam

Sebagai suatu subyek pelajaran, pendidikan agama Islam mempunyai fungsi berbeda dengan subyek pelajaran yang lain. Ia dapat memiliki fungsi yang bermacam-macam, sesuai dengan tujuan yang ingin dicapai masing-masing lembaga pendidikan.18 Namun secara umum, Abdul majid mengemukakan bahwa kurikulum pendidikan agama Islam untuk sekolah/madrasah berfungsi sebagai berikut?

1. Pengembangan, yaitu meningkatkan keimanan dan ketakwaan peserta didik kepada Allah SWT yang telah ditanamkan dalam lingkungan keluarga. Pada dasarnya dan pertama-tama kewajiban dilakukan oleh setiap orang tua dalam keluarga. Sekolah berfungsi untuk menumbuhkan menanamkan keimanan dan ketakwaan dilakukanoleh setiap orang tua dalam keluarga. Sekolah berfungsi untuk menumbuh kembangkankan lebih lanjut dalam diri anak melalui bimbingan, pengajaran dan pelatihan agar keimanan dan ketakwaan tersebut dapat berkembang secara optimal sesuai dengan tingkat perkembangannya.

2. Penanaman nilai, sebagai pedoman hidup untuk mencari kebahagiaan hidup di dunia dan akhirat Penyesuaian mental, yaitu untuk menyesuaikan diri dengan lingkungan-nya baik lingkungan fisik maupun lingkungan sosial dan dapat mengubah lingkungannya sesuai dengan ajaran agama Islam.

3. Penyesuaian menta, yaitu untuk menyesuaikan diri dengan lingkungannya baik lingkungan fisik maupun lingkungan sosial dan dapat mengubah lingkungannya sesuai dengan ajaran agama Islam.

4. Perbaikan, yaitu untuk memperbaiki kesalahan-kesalahan, kekurangan-kekurangan dan kelemahan-kelemahan peserta didik dalam keyakinan, pemahaman dan pengalaman ajaran dalam kehidupan sehari-hari.

\footnotetext{
${ }_{9}^{9}$ Abdul Majid dan Dian Andayani, Op. Cit. 136
} 
5. Pencegahan, yaitu untuk menangkal hal-hal negatif dari lingkungannya atau dari budaya lain yang dapat membahayakan dirinya dan menghambat perkembangannya menuju manusia Indonesia seutuhnya.

6. Pengajaran, tentang ilmu pengetahuan keagamaan secara umum (alam nyata dan nir-nyata), sistem dan fungsionalnya.

7. Penyaluran, yaitu untuk menyalurkan anak-anak yang memiliki bakat khusus di bidang agama Islam agar bakat tersebut dapat berkembang secara optimal sehingga dapat dimanfaatkan untuk dirinya sendiri dan bagi orang lain.

\section{d. Pembentukan Karakter Sosial Pada Anak}

\section{Metode Pembentukan Karakter}

Metode pembentukan karakter berkaitan langsung dengan tahapan perkembangannya. Tahapan tersebut terbagi dalam tiga tahapan yaitu tahapankarakter lahiriyah (karakter anakanak), tahapan karakter berkesadaran (karakter remaja) dan tahapan kontrol internal atas karakter (karakter dewasa). Pada tahapan lahiriyah metoda yang digunakan adalah pengarahan, pembiasaan, keteladanan, penguatan (imbalan) dan pelemahan (hukuman) serta indoktrinasi. Sedangkan pada tahapan perilaku berkesadaran, metoda yang digunakan adalah penanaman nilai melalui dialog yang bertujuan meyakinkan, pembimbingan bukan instruksi dan pelibatan bukan pemaksaan. Dan pada tahapan kontrol internal atas karakter maka metoda yang diterapkan adalah perumusan visi dan misi hidup pribadi, serta penguatan akan tanggungjawab langsung kepada Allah. Tahapan diatas lebih didasarkan pada sifat daripada umur. $^{10}$

2. Proses Pembentukan Karakter

a. Karakter terbentuk setelah mengikuti proses sebagai berikut $:^{11}$

1. Adanya nilai yang diserap seseorang dari berbagai sumber, mungkin agama, ideologi, pendidikan, temuan sendiri atau lainnya.

2. Nilai membentuk pola fikir seseorang yang secara keseluruhan keluar dalam bentuk rumusan visinya.

\footnotetext{
${ }^{10}$ Amilda. Universitas Islam Negeri Raden Fatah. Pembentukan Karakter Anak Usia Dinimelalui Pembiasaan..Jurnal Raden Fatah

11 Ibid
} 
3. Visi turun ke wilayah hati membentuk suasana jiwa yang secara keseluruhan membentuk mentalitas.

4. Mentalitas mengalir memasuki wilayah fisik dan melahirkan tindakan yang secara keseluruhan disebut sikap. Sikap-sikap yang dominan dalam diri seseorang yang secara keseluruhan mencitrai dirinya adalah apa yang disebut sebagai kepribadian atau karakter.

5. Proses pembentukan mental tersebut menunjukan keterkaitan antara fikiran, perasaan dan tindakan. Dari akal terbentuk pola fikir, dari fisik terbentuk menjadi perilaku

e. Pendidikan Agama Islam Dalam Pembentukan Karakter Anak Didik

Pendidikan agama Islam sangat di butuhkan dalam mendukung pembentukan karakter anak. Dengan adanya pendidikan agama bisa menjadikan anak mempunyai karakter yang baik . Konsep pendidikan karakter sebenarnya telah ada sejak zaman rasulullah SAW. Hal ini terbukti dari perintah Allah bahwa tugas pertama dan utama Rasulullah adalah sebagai penyempurna akhlak bagi umatnya. Pembahasan substansi makna dari karakter sama dengan konsep akhlak dalam Islam, keduanya membahas tentang perbuatan prilaku manusia. AlGhazali menjelaskan jika akhlak adalah suatu sikap yang mengakar dalam jiwa yang darinya lahir berbagai perbuatan dengan mudah dan gampang tanpa perlu adanya pemikiran dan pertimbangan. $^{12}$

Suwito menyebutkan bahwa akhlak sering disebut juga ilmu tingkah laku atau perangai, karena dengan ilmu tersebut akan diperoleh pengetahuan tentang keutamaankeutamaan jiwa; bagaimana cara memperolehnya dan bagaiman membersihkan jiwa yang telah kotor. $^{13}$ Sedangkan arti dari Karakter adalah nilai-nilai yang khas-baik (tahu nilai kebaikan, mau berbuat baik, nyata berkehidupan baik, dan berdampak baik terhadap lingkungan) yang terpateri dalam diri dan terejawantahkan dalam perilaku. Karakter secara koheren memancar dari hasil olah pikir, olah hati, olah raga, serta olah rasa dan karsa seseorang atau sekelompok orang. ${ }^{14}$

Pembahasan tentang pengertian dasar antara akhlak dan karakter tersebut diatas mengisyaratkan substansi makna yang sama yaitu masalah moral manusia; tentang

\footnotetext{
12 Abidin Ibnu Rusn, Pemikiran Al-Ghazali Tentang Pendidikan, (Yogyakarta: Pustaka Pelajar, 1998), h. 99

${ }^{13}$ Suwito, Filsafat Pendidikan Akhlak Ibn Miskawaih, (Yogyakarta: Belukar, 2004), h. 31

${ }_{14}$ Abdullah Nasih Ulwan, Pedoman Pendidikan Anak Dalam Islam, Terj Sefullah Kamalie Dan Hery Noer Ali, Jilid 2, (Semarang: Asy-Syifa, Tt), h. 44
} 
pengetahuan nilai-nilai yang baik, yang seharusnya dimiliki seseorang dan tercermin dalam setiap prilaku serta perbuatannya. Prilaku ini merupakan hasil dari kesadaran dirinya sendiri. Seseorang yang mempunyai nilai-nilai baik dalam jiwanya serta dapat mengaplikasikannya dalam kehidupan sehari-hari disebut orang yang berakhlak atau berkarakter. Akhlak atau karakter dalam Islam adalah sasaran utama dalam pendidikan. Hal ini dapat dilihat dari beberapa hadits nabi yang menjelaskan tentang keutamaan pendidikan akhlak salah satunya hadits berikut ini: "ajarilah anak-anakmu kebaikan, dan didiklah mereka". ${ }^{15}$

Konsep pendidikan didalam Islam memandang bahwa manusia dilahirkan dengan membawa potensi lahiriah yaitu:1) potensi berbuat baik terhadap alam, 2) potensi berbuat kerusakan terhadap alam, 3) potensi ketuhanan yang memiliki fungsi-fungsi non fisik. Ketiga potensi tersebut kemudian diserahkan kembali perkembangannya kepada manusia.

Pendidikan agama islam sangat penting bagi anak didik dam membentuk dan mengembangkan karakter siswa. Pendidikan agama islam dan moral harus saling berinteraksi satu sama lain agar dalam sosial masyarakat terjadi saling menghormati dan saling membatu satu dengan yang lain

\section{KESIMPULAN}

Pendidikan agama Islam sangat penting bagi sosial masyarakat karena dengan adanya pendidikan agama islam bisa membentuk karakter yang baik dengan melakukan perbuatan yang sesuai yang diajarkan oleh agama islam dan dapat menambah ketagwaan kepada Allah SWTT. Pendidikan Agama Islam juga merupakan pondasi yang utama dalam pendidikan moral dan akhlak yang terbentuk dalam karakter anak didik salah satunya dalam bersosial masyarakat agar anak menjadi memahami cara menghormati, cara sopan santun dalam bersosial masyarakat seperi yang diajarkan dalam agama islam.

\section{DAFTAR PUSTAKA}

PAI, A. P. P. A. I. (1997). Pendidikan agama islam. Jurnal, diakses pada, 18(10), 2018.

Ningsih, T. (2019). Peran Pendidikan Islam Dalam Membentuk Karakter Siswa Di Era Revolosi Industri 4.0 Di Madrasah Tsanawiyah Negeri 1 Banyumas. Insania: Jurnal Pemikiran Alternatif Kependidikan, 24(2), 220-231.

\footnotetext{
15 Suwito, Op.Cit, h. 46
} 
Elihami, E., \& Syahid, A. (2018). Penerapan Pembelajaran Pendidikan Agama Islam dalam Membentuk Karakter Pribadi yang Islami. Edumaspul: Jurnal Pendidikan, 2(1), 79-96.

Mahmud, Ali Abdul Halim, 2003, Tarbiyah Khuluqiyah Pembinaan Diri Menurut Konsep Nabawi, Terj Afifudin, Solo, Media Insani.

Suwito, 2004, Filsafat Pendidikan Akhlak Ibn Miskawaih, Yogyakarta, Belukar.

Ulwan, Abdullah Nasih, Pedoman Pendidikan Anak Dalam Islam, Terj Sefullah Kamalie Dan Hery Noer Ali, Jilid 2, Semarang, Asy-Syifa.

Ainiyah Nur (2013). Pembentukan Karakter Melalui Pendidikan Agama Islam. Jurnal Al-Ulum (13)1 